\title{
Barbárie e neoconservadorismo: os desafios do projeto ético-político*
}

\section{Barbarism and neoconservatism: the challenges of the ethical-political project}

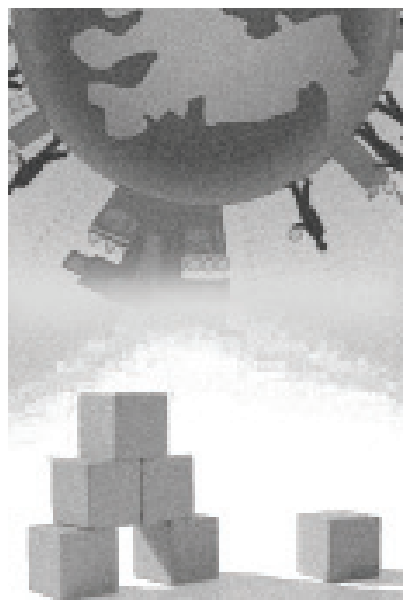

Maria Lucia S. Barroco**

Resumo: Este artigo foi desenvolvido a partir de Palestra realizada no Seminário "30 Anos do Congresso da Virada", em São Paulo, em 2009. Analisando os desafios do projeto ético-político na atual conjuntura, assinala as principais determinações da sociabilidade contemporânea para evidenciar o ethos dominante no cenário do neoliberalismo pós-moderno e as formas de ser que favorecem o neoconservadorismo e criam obstáculos à viabilização dos valores e pressupostos do Código de Ética Profissional.

Palavras-chave: Ética. Ethos. Projeto ético-político. Neoconservadorismo. Neoliberalismo pós-moderno

\begin{abstract}
This article was developped from the Seminar "30 Years of Congresso da Virada", which was held in São Paulo in 2009. Analyzing the challenges of the ethical-political project at the current moment, it points out the main determinations of contemporary sociability in order to highlight the dominant ethos in the post-modern neoliberalism setting and the aspects that both favor neoconservatism and hamper the viability of the values and assumptions from the Code of Professional Ethics.
\end{abstract}

Keywords: Ethics. Ethos. Ethical-political project. Neoconservatism. Post-modern neoliberalism

* Esse artigo foi desenvolvido a partir do texto original da Palestra realizada no seminário "30 anos do Congresso da Virada", na mesa "Diálogos sobre os desafios do projeto ético-político do Serviço Social", em novembro de 2009, em São Paulo.

** Assistente social, professora de Ética Profissional e coordenadora do Núcleo de Estudos e Pesquisa em Ética e Direitos Humanos (Nepedh) do Programa de Estudos Pós-Graduados em Serviço Social da PUC-SP —São Paulo, Brasil.E-mail: 1ubarro@uol.com.br. 


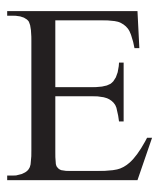

sse texto visa uma reflexão sobre os desafios do projeto ético-político na atual conjuntura, sob a perspectiva da ética. Isso requer uma breve análise da sociabilidade contemporânea, visando assinalar algumas determinações que incidem sobre a vida cotidiana, criando necessidades e motivando respostas de caráter moral e político.

As transformações operadas no capitalismo mundial pela ofensiva do capital, a partir da década de 1970 do (Netto e Braz, 2006), resultaram no agravamento da desigualdade estrutural e na degradação da vida humana e da natureza. Aprofundando a exploração do trabalho, o desemprego estrutural e conjuntural, instituindo novas formas de trabalho precário e destruindo direitos conquistados historicamente pelos trabalhadores, entre outros, esse processo intervém na vida dos indivíduos, criando demandas e respostas à insegurança vivenciada objetiva e subjetivamente na vida cotidiana. As formas de (re)produção social imprimem uma nova dinâmica ao conjunto das relações sociais:

Em sua forma contemporânea, a sociedade capitalista caracteriza-se pela fragmentação de todas as esferas da vida social, desde a produção, com a dispersão espacial e temporal do trabalho, até a destruição dos referenciais que balizavam a identidade de classe e as formas de luta de classes. A sociedade aparece como uma rede móvel, instável, efêmera de organizações particulares definidas por organizações particulares e programas particulares, competindo entre si. (Chaui, 2006, p. 324)

A apreensão fragmentada da realidade e a percepção de que as relações sociais são efêmeras e instáveis decorrem de vivências objetivas, num contexto de empobrecimento e de instabilidade e desregulamentação das relações de trabalho. A reificação que invade todas as esferas da vida social (Netto, 1981) favorece essa apreensão, pois contribui para ocultar a essência desses processos que aparecem, em sua aparência reificada, como se fossem fenômenos naturais e absolutos. Além do mais, a ideologia dominante sedimenta essa naturalização, em sua justificação da dinâmica capitalista.

O pensamento dominante no capitalismo contemporâneo - a ideologia neoliberal e seu subproduto, a ideologia pós-moderna -, exerce a função social de justificação das transformações operadas na vida social pela ofensiva do capital. É dessa forma que a insegurança, a instabilidade e a fragmentação são disseminadas como componentes ontológicos constitutivos de uma etapa histórica intransponível: a "era pós-moderna” (Chaui, 2006; Harvey, 2005). 
Valorizando a instabilidade e a dispersão, a ideologia neoliberal pós-moderna declara o "fracasso": dos projetos emancipatórios, das orientações éticas pautadas em valores universais, da razão moderna, da ideia de progresso histórico e de totalidade. $\mathrm{O}$ estímulo à vivência fragmentada centrada no presente (resumida ao aqui e ao agora, sem passado e sem futuro), ao individualismo exacerbado, num contexto penetrado pela violência, dá origem a novas formas de comportamento, que, segundo Chaui (2006, p. 324), buscam "algum controle imaginário sobre o fluxo temporal”.

As tentativas de capturar o passado como memória subjetiva, por meio de objetos ou de uma memória virtual, com lista de amigos pela internet (Idem, p. 325), revelam uma das características mais marcantes da sociabilidade contemporânea: a tendência ao intimismo, o retorno às questões da vida privada, que revelam que:

A insegurança e o medo levam ao reforço de antigas instituições, sobretudo a família e o clã como refúgios contra um mundo hostil, ao retorno de formas místicas e autoritárias ou fundamentalistas de religião e à adesão à imagem da autoridade política forte ou despótica. Dessa maneira, bloqueia-se o campo da ação intersubjetiva e sociopolítica, oculta-se a luta de classes e fecha-se o espaço público, que se encolhe diante da ampliação do espaço privado. (Chaui, 2006, p. 325)

Trata-se, pois, de condições favoráveis à desqualificação da política, condições facilitadas por inúmeros fatores históricos, especialmente das determinações que incidiram sobre as possibilidades concretas de organização política das classes trabalhadoras. Não podemos ignorar, nesse cenário, os desdobramentos do fim das experiências do socialismo.

O processo de mundialização do capital (Chesnais, 1996) e a implantação das políticas neoliberais - com todas as suas consequências —, implicou o empobrecimento e a desmobilização política dos trabalhadores: contribuiu para a crise dos partidos e das entidades de classe dos trabalhadores, e, como o fim das experiências socialistas, para que a apologética capitalista propagasse o seu triunfo, anunciando o "fim da história".

É interessante observar que esse contexto favoreceu a reorganização dos movimentos de direita, especialmente na Europa. Outro dado relevante é o que 
aponta a origem de classe dos movimentos de direita e sua vinculação com o processo de mundialização do capital, no contexto do neoliberalismo. Estudos têm mostrado (Carneiro, 2004) que movimentos neonazistas vinculados a partidos de extrema direita, como os skinheads, surgiram nos anos 1970, com forte determinação do desemprego estrutural e da precarização das condições de vida das classes trabalhadoras: seus integrantes são jovens, filhos de operários, trabalhadores do subúrbio e das periferias das grandes cidades e minoritariamente das classes médias empobrecidas.

Segundo dados do Serviço Secreto Alemão (Carneiro, 2004, p. 136), após a queda do Muro de Berlim, em 1999, existiam cerca de 3 mil skinheads na antiga Alemanha Oriental e 1.200 na Ocidental. Ocorreram 2.500 atentados de caráter xenófobo na Alemanha em 1992, e, em 1993, 6 mil, constatando-se que vários deles tiveram o apoio da população (Ibidem). No Brasil, tendo como alvo os negros, judeus, nordestinos, homossexuais e comunistas, os "Carecas do ABC" e outros grupos apoiados pela TFP (Tradição, Família e Propriedade) — movimento católico paramilitar ultraconservador —, têm a mesma origem socioeconômica (Ibidem).

As guerras, os conflitos etnorraciais e religiosos, assim como o fim das experiências socialistas, têm provocado êxodos por todo o mundo, revelando um fenômeno contemporâneo diretamente vinculado à barbarização da vida: a xenofobia. Formas coletivas institucionalizadas de xenofobia e de intolerância dirigidas contra imigrantes, estrangeiros, ciganos, desempregados etc. se espraiam por todo o mundo, evidenciando a violência, como elemento presente no cotidiano (Ianni, 2004).

A ideologia dominante exerce uma função ativa no enfrentamento das tensões sociais, para manter a ordem social em momentos de explicitação das contradições sociais e das lutas de classe. Numa sociedade de raízes culturais conservadoras e autoritárias como a brasileira (Chaui, 2000), a violência é naturalizada; tende a ser despolitizada, individualizada, tratada em função de suas consequências e abstraída de suas determinações sociais. A ideologia neoliberal — veiculada pela mídia, em certos meios de comunicação como o rádio, a TV, a internet e revistas de grande circulação - falseia a história, naturaliza a desigualdade, moraliza a "questão social", incita o apoio da população a práticas fascistas: o uso da força, a pena de morte, o armamento, os linchamentos, a xenofobia. 
O modo de ser adequado à (re)produção das relações sociais burguesas, na contemporaneidade, é determinado pelas formas de sociabilidade aqui assinaladas. No interior de uma dinâmica histórica complexa e contraditória, da luta de classes e da oposição entre projetos sociais, entre ideias e valores, se processa um modo de ser dominante, fortalecido pela base material de suas ideias. Quero dizer que a sociedade burguesa é fundada na propriedade privada dos meios de produção e que isso fornece a base material para a reprodução de um ethos fundado na posse privada de objetos.

Todos os valores oriundos da sociabilidade burguesa e do ethos burguês, como o consumismo e a competição, se apoiam, portanto, no princípio da propriedade privada, incorporado pelos indivíduos como sinônimo da felicidade, de liberdade, de realização pessoal. É claro que os valores vão adquirindo significações de acordo com o desenvolvimento da sociedade burguesa. Como vimos, no neoliberalismo pós-moderno o consumismo adquire contornos exacerbados, o individualismo se expressa de modo privatista, voltado para o intimismo.

A valorização da posse privada dos objetos no lugar das relações humanas levada ao extremo caracteriza o ethos dominante na sociedade contemporânea: sua igreja é o shopping; seu reino é o mundo virtual; seus mitos são as imagens que - fetichizadas em um espaço imaginário — desmaterializam o mundo real, criando uma segunda vida onde os desejos consumistas podem ser satisfeitos sem a presença do outro: o eterno empecilho à sua liberdade.

Ídolos e mitos são reproduzidos incessantemente pelo mercado da publicidade e pela indústria cultural: Barbies, séries de TV, filmes, novelas, propagandas para cada indivíduo cuja identidade social é dada pelo seu potencial de consumo. Incentiva-se o consumismo e tudo o que desvie os indivíduos da vida pública e da política: questões pessoais, de autoajuda, problemas íntimos, familiares, psicológicos: formas de controle das tensões sociais e de reprodução do modo de ser necessário à apologia do capital. Vê-se, portanto, que estamos em face de uma cultura claramente conservadora.

O neoconservadorismo busca legitimação pela repressão dos trabalhadores ou pela criminalização dos movimentos sociais, da pobreza e da militarização da vida cotidiana. Essas formas de repressão implicam violência contra o outro, e todas são mediadas moralmente, em diferentes graus, na medida em que se objetiva a negação do outro: quando o outro é discriminado lhe é negado o direito de existir como tal ou de existir com as suas diferenças. 
Certamente, parte da sociedade não reproduz essa ideologia e combate essas práticas: os movimentos populares democráticos, milhares de sujeitos políticos que no mundo inteiro se manifestam de formas variadas em oposição à desumanização, em confronto com o capital, na resistência ao avanço das políticas neoliberais: os Piqueteiros e as Mães da Praça de Maio, na Argentina; os Zapatistas, no México; o Movimento dos Trabalhadores sem Terra (MST), no Brasil, os movimentos de indígenas, na Bolívia e no Equador, outras centenas de movimentos populares democráticos que desde 2001 se reúnem nas edições do Fórum Social Mundial em torno da ideia de que "outro mundo é possível"; os partidos políticos e as entidades de classe dos trabalhadores, no processo de luta pela hegemonia em busca da construção de novos projetos e de uma nova sociedade. O Serviço Social tem uma trajetória de engajamento nessas lutas.

No entanto, não podemos ignorar que o cenário histórico tem revelado uma crise de hegemonia das esquerdas e dos projetos socialistas de modo geral. É nesse contexto que o conservadorismo tem encontrado espaço para se reatualizar, apoiando-se em mitos, motivando atitudes autoritárias, discriminatórias e irracionalistas, comportamentos e ideias valorizadoras da hierarquia, das normas institucionalizadas, da moral tradicional, da ordem e da autoridade. Uma das expressões dessa ideologia é a reprodução do medo social.

Temos medo de algo real ou imaginário. Quando o objeto do medo é tratado moralmente, torna-se sinônimo do "mal". Ao mesmo tempo em que a moral serve ideologicamente para dar identidade ao objeto do medo ela passa a justificar uma inversão na moralidade do sujeito: na luta contra o "mal" toda moral é suspensa, tudo é válido: o "mal" acaba justificando o próprio "mal": a morte, a tortura, a eliminação do outro. Quando a ideologia do medo é internalizada na vida cotidiana, uma situação de insegurança excepcional passa a ser vivida como algo que pode vir a ocorrer a qualquer momento, um estado de alerta típico de situações de guerra (Batista, 2003a; Costa, 1993).

Após os atentados de 2001, nos EUA, centenas de filmes, seriados e programas virtuais foram produzidos incentivando a insegurança e a ideia moral do outro como ameaça permanente. Não é preciso dizer quem é ele. 24 horas, um dos seriados de maior sucesso nos EUA, passado no Brasil, deixa isso evidente: na série, nenhum lugar do mundo é seguro; a qualquer momento, a vida pode se tornar um inferno pelas mãos do "mal": terroristas, criminosos, trafi- 
cantes. A política de tolerância zero e o Estado policial seguem essa lógica neofascista reproduzida nos EUA e na Europa, na discriminação contra os imigrantes, a exemplo das milícias populares na Itália; na perseguição aos ciganos, na França; e, no Brasil, na criminalização dos movimentos sociais e da pobreza, e, na atual institucionalização da militarização do cotidiano pelo Estado, no combate ao narcotráfico.

O filme brasileiro Tropa de elite, de 2007, que perdeu o Oscar para outro filme também violento cujo título é sugestivo - Por que os fracos não têm vez —, revela essa lógica. $\mathrm{O}$ violento treinamento físico e o condicionamento psicológico exigido dos integrantes do Bope (Batalhão de Operações Especiais) têm por finalidade a sua desumanização, o que significa incorporar a ideologia da guerra permanente, permitindo a suspensão de qualquer resquício de uma moralidade humanitária na consciência dos agentes: guerra é guerra. Diante dessa palavra-chave, qualquer moral é suspensa: tudo é válido: os fins justificam os meios (Barroco, 2008).

Estudos sobre a violência no Rio de Janeiro (Batista, 2003a), apontam essa ideologia na guerra ao narcotráfico: uma herança da doutrina de segurança nacional usada na ditadura: a ideologia da guerra contra o inimigo interno. $\mathrm{Na}$ guerra atual o discurso é moral e religioso: a droga aparece como uma metáfora diabólica contra a civilização cristã: uma cruzada contra o mal, uma guerra santa contra o traficante herege (Idem, p. 40). Repete-se a lógica do Bope: guerra é guerra.

Essas breves observações tiveram por finalidade apontar um cenário propício à objetivação de ideias e práticas neoconservadoras e individualistas que obviamente não se restringem às aqui apresentadas, mas que coexistem com formas de oposição e de resistência, a exemplo de inúmeras ações de defesa dos direitos humanos, de denúncias, de resistências, de mobilizações e de lutas constitutivas do universo das forças políticas democrático-populares e do conjunto das classes trabalhadoras brasileiras.

Assim, considerando que o cenário atual pode ser facilitador da reatualização de projetos conservadores na profissão, mas entendendo também que nossa trajetória de lutas, inserida no universo de resistências da sociedade brasileira permite esse enfrentamento, quero afirmar que do ponto de vista ético-político a busca de ruptura com o conservadorismo no Serviço Social — princípio e objetivo que norteou (norteia) o projeto ético-político nesses trinta anos -é 
neste momento renovado como um grande desafio: o enfrentamento de suas novas formas ético-políticas e manifestações teórico-práticas.

Para finalizar, assinalo algumas questões para reflexão e debate:

- Em primeiro lugar cabe refletir sobre as bases sociais do nosso projeto ético-político. Sabemos que seu surgimento foi determinado fundamentalmente em função de certos(as) sujeitos e condições históricas: o protagonismo da profissão, em seus setores progressistas, contando com o processo de reorganização das classes trabalhadoras e dos movimentos democrático-populares, no contexto de redemocratização da sociedade brasileira dos anos 1980. Sendo assim, a nossa força política está articulada, ainda que não seja de forma mecânica, ao avanço dessa base social, que tem como protagonistas os sujeitos de nossa intervenção profissional: as classes trabalhadoras.

- Nesse sentido, o enfrentamento do neoconservadorismo, sob o ponto de vista profissional, é de caráter político em dois aspectos articulados. Por um lado, é preciso que nossa organização política esteja fortalecida e renovada com novos quadros, supondo o trabalho de base, junto à categoria, com as entidades de representação, as unidades de ensino, os profissionais e alunos. Por outro lado, só conseguiremos consolidar politicamente o nosso projeto, na direção social pretendida, se tivermos uma base social de sustentação; logo, é fundamental a articulação com os partidos, sindicatos e entidades de classe dos trabalhadores, com os movimentos populares e democráticos, com as associações profissionais e entidades de defesa de direitos. E o avanço político do nosso projeto está articulado ao avanço dessas forças sociais mais amplas. Ao mesmo tempo, é preciso ter clareza de que essa luta é limitada, uma vez que ela envolve dimensões que extrapolam a profissão.

- A reatualização do conservadorismo é favorecida pela precarização das condições de trabalho e da formação profissional, pela falta de preparo técnico e teórico, pela fragilização de uma consciência crítica e política, o que pode motivar a busca de respostas pragmáticas e irracionalistas, a incorporação de técnicas aparentemente úteis em um contexto fragmentário e imediatista. A categoria não está imune aos processos de alienação, à influência do medo social, à violência, em suas formas 
subjetivas e objetivas. Isso coloca um imenso desafio ao projeto ético-político, na medida em que a sua viabilização não depende apenas da intencionalidade dos profissionais, tendo em vista as suas determinações objetivas, nem se resolve individualmente. Além disso, não podemos ignorar que o conservadorismo tem raízes históricas na profissão: para parcela da categoria, trata-se de uma opção política conscientemente adotada. Nesse sentido, a conjuntura pode favorecer a sua reatualização, sob novas roupagens e demandas.

- A dimensão ética desse enfrentamento supõe dimensões teóricas e políticas. O neoconservadorismo tem diversas formas de expressão. Seu conhecimento exige a pesquisa e o estudo, em suas configurações na sociedade contemporânea e brasileira, como pensamento teórico e projeto político-ideológico e em seu rebatimento particular na profissão, em sua dimensão ética e política. É preciso conhecer nossa categoria, nossos alunos e a população que atendemos para que não sejam reproduzidos mitos e idealizações.

- A ideologia neoconservadora tende a se irradiar nas instituições sob formas de controle pautadas na racionalidade tecnocrática e sistêmica tendo por finalidade a produtividade, a competitividade e a lucratividade, onde o profissional é requisitado para executar um trabalho repetitivo e burocrático, pragmático e heterogêneo, que não favorece atitudes críticas e posicionamentos políticos. Instituições voltadas para a coerção, como prisões, delegacias, casas para jovens infratores, abrigos, instituições jurídicas, demandam ao assistente social atividades de controle e censura: avaliações de situações que envolvem os sujeitos criminalizados moralmente e julgados como irrecuperáveis pelo poder dominante. A ideologia dominante está incorporada nessas instituições de diversas formas, como mostram vários estudos (Wacquant, 2007; Batista, 2003a, 2003b). O discurso dominante é o da naturalização e moralização da criminalidade; as práticas de encaminhamento são seletivas, baseadas, muitas vezes, em critérios que envolvem avaliações morais, de classe e condição social. $\mathrm{O}$ assistente social precisa estar capacitado para enfrentar esse discurso, de forma a não reproduzi-lo reeditando o conservadorismo profissional, a não atender às novas requisições do estado policial, para não incorporá-las exercendo a coerção. 
Esse enfrentamento ético-político supõe estratégias coletivas de capacitação e organização política, de discussão nos locais de trabalho, de articulação com outras categorias, entidades e com os movimentos organizados da população usuária.

- O enfrentamento teórico do neoconservadorismo é um empreendimento que supõe a desmistificação dos seus pressupostos e dos seus mitos irracionalistas que falseiam a história. A crítica dos valores é uma tarefa específica da ética, em sua explicitação do significado do uso ideológico dos valores. Nos últimos vinte anos a ética se tornou um discurso abstrato: diferentes sujeitos falam em ética sem explicitar o seu significado, a sua direção, o projeto que defendem. O Código de Ética é utilizado como uma "senha"; o projeto ético-político transformou-se num "mito". Mas o Código de Ética tem uma concepção que dá significado aos seus valores; eles são abstratos. Entretanto, quando são separados de sua concepção tornam-se abstrações que servem para falsear a história.

- É também um desafio ético o incentivo à criação de núcleos de pesquisa e de estudos voltados para a capacitação em ética e direitos humanos, demandas dos alunos e profissionais que precisam ser atendidas de forma qualificada, para identificar análises irracionalistas, presentes no ideário pós-moderno, que negam a universalidade dos valores, a perspectiva de totalidade, a luta de classes, o trabalho, o marxismo, afirmando um pluralismo apoiado no ecletismo e na relativização da verdade objetiva, passível de ser apreendida pela razão dialética. Outro desafio é desenvolver a análise histórica dos direitos humanos, para não repetirmos as visões abstratas que remetem aos postulados tradicionais do Serviço Social, reeditando a concepção de "pessoa humana" com citações de Marx.

- Formas de capacitação que têm se desenvolvido através da utilização de meios virtuais, têm contribuído para retirar do ensino a possibilidade interativa exigida pelo conhecimento crítico. Cursos à distância, salas de discussão virtual, leituras virtuais, entre outras, são algumas das formas de reprodução do neoliberalismo contemporâneo: o indivíduo isolado e passivo diante de uma máquina se comunicando com imagens e ideias que substituem as relações humanas por relações 
entre objetos e imagens fetichizadas. Além disso, a utilização institucionalizada dos meios virtuais envolve inúmeras questões éticas, como a divulgação de dados sigilosos, além de permitir a possibilidade de plágio etc.

- As instituições de ensino, responsáveis pela transmissão do conhecimento, tendem a se adequar à lógica do mercado, em empresas que vendem mercadorias: a força de trabalho de professores, superexplorados e desapropriados dos meios de seu trabalho sem tempo para a pesquisa, para o estudo e para a construção do conhecimento como totalidade. O produto final dessa precarização em curso, nas instituições mercantis, é o empobrecimento material e espiritual da juventude, que, uma vez profissionalizada, tem poucos recursos para realizar seus possíveis ideais, já fragilizados pelas condições objetivas da sociabilidade burguesa.

- Só é possível fazer essas observações críticas e pretender enfrentá-las porque já dispomos — enquanto categoria profissional — de um acúmulo teórico e político que nos capacitou a apreender a realidade além de sua aparência, em uma perspectiva de histórica e de totalidade, ou seja, buscando perceber a relação entre os fenômenos em suas mais íntimas e ocultas determinações. Ora, esse acúmulo foi obtido por meio de um longo e árduo processo de trinta anos; um esforço teórico e político que contou com o trabalho de assistentes sociais, mulheres e homens que aqui estão nesse encontro e tantos outros que não estão presentes: um processo de luta política que foi travado a duras penas durante a ditadura e depois dela por profissionais que fizeram a Virada em 1979, pelos que assumiram a direção das entidades, pelos alunos e alunas que encamparam essa luta e a renovam cotidianamente.

- Se temos uma herança conservadora, temos também uma história de ruptura: um patrimônio conquistado que é nosso, mas cujos valores, cujas referências teóricas e cuja força para a luta não foram inventadas por nós. Trata-se de uma herança que pertence à humanidade e que nós resgatamos dos movimentos revolucionários, das lutas democráticas, do marxismo, do socialismo, e incorporamos ao nosso projeto.

- Os pilares que sustentam o nosso projeto ético-político em sua dimensão de ruptura - o marxismo, o ideário socialista da emancipação 
humana, o compromisso com as classes trabalhadoras e com a realização de um Serviço Social que atenda os seus reais interesses e necessidades, a busca de ruptura com o conservadorismo, em todas as suas formas - constituem o nosso mais valioso patrimônio que, espero, possamos cuidar dele com muito amor e coragem.

Recebido em mar./2011 n Aprovado em abr./2011

\section{Referências bibliográficas}

ALVES, J. A Lindgren. Os direitos humanos na pós-modernidade. São Paulo: Perspectiva, 2005.

ANDERSON, Perry. Balanço do neoliberalismo. In: SADER, Emir; GENTILLI, Pablo (Orgs.). Pós-Neoliberalismo: as políticas sociais e o Estado democrático. Rio de Janeiro: Paz e Terra, 1995.

BATISTA, Vera Malaguti. Dificeis ganhos fáceis: drogas e juventude pobre no Rio de Janeiro. Rio de Janeiro: Revan, 2003a.

. O medo na cidade do Rio de Janeiro. Rio de Janeiro: Revan, $2003 \mathrm{~b}$.

BARROCO, Maria Lucia Silva. A historicidade dos direitos humanos. In: FORTI, Valeria; GUERRA, Yolanda. Ética e direitos: ensaios críticos. Rio de Janeiro: Lumen Júris, 2009a.

. Ética: fundamentos sócio históricos. 2. ed. São Paulo: Cortez, 2009b. (Col. Biblioteca Básica para o Serviço Social, v. 4.)

. Bandidos, mitos e bundas: moral e cinema em tempos violentos. Revista Sesc Melhores Filmes. São Paulo: SESC-SP, 2008.

. Ética, direitos humanos e diversidade. Revista Presença Ética, Recife, n. 3, 2003.

BRAZ, Marcelo. Notas sobre o projeto ético-político. In: CRESS-7 ${ }^{a}$ Região. Assistente social: ética e direitos. Rio de Janeiro, 2005.

BURKE, Edmund. Reflexões sobre a revolução em França. 2. ed. Brasília: Editora Universidade de Brasília, 1997. 
CARNEIRO, M. L. T. Racismo nazista: a era nazi e o antisemitismo. In: PINSKY, Jaime; PINSKY Carla B. (Orgs.). Faces do fanatismo. São Paulo: Contexto, 2001.

. Neonazismo: o renascer da besta. In: PINSKY, Jaime; PINSKY Carla B. (Orgs.). Faces do fanatismo. São Paulo: Contexto, 2004.

CHAUI, Marilena. Direitos humanos e medo. In: FESTER, A. C. R. (Orgs.). Direitos humanos e... São Paulo: Brasiliense, 1989.

. Brasil: mito fundador e sociedade autoritária. São Paulo: Fundação Perseu Abramo, 2000.

2006.

.Cultura e democracia: o discurso competente e outras falas. São Paulo: Cortez,

CHESNAIS, François. A mundialização do capital. São Paulo: Xamã, 1996.

CONSELHO FEDERAL DE SERVIÇO SOCIAL (CFESS). Código de ética do assistente social. Brasilia: CFESS, 1993.

COSTA, Jurandir Freire. O medo social. In: Veja: 25 anos — reflexões para o futuro. São Paulo: Abril, 1993.

HARVEY, David. Condição pós-moderna. São Paulo: Moderna, 2005.

HAYEK, Friedrich. Principios de una orden social liberal. Madri: Union Editorial, 2001.

HELLER, Agnes. O cotidiano e a história. 6. ed. Rio de Janeiro: Paz e Terra, 2000.

IAMAMOTO, Marilda. Serviço em tempo de capital fetiche. São Paulo: Cortez, 2007.

IANNI, Octávio. Capitalismo, violência e terrorismo. Rio de Janeiro: Civilização Brasileira, 2004.

JAMESON, Friedrich. A virada cultural: reflexões sobre o pós-moderno. São Paulo: Civilização Brasileira, 2006.

KEHL, Maria Rita; BUCCI, Eugênio. Videologias. São Paulo: Boitempo, 2004. (Col. Estado de Sítio.)

LUKÁCS, Georg. O problema da ideologia. In: . Per l'ontologia dell'essere sociale. Tradução Ester Waisman. Roma: Riunit, 1981.

. El asalto a la razón: la trayectoria del irracionalismo desde Schelling hasta Hitler. Barcelona: Grijalbo, 1968.

MacPHERSON, C. B. A teoria política do individualismo possessivo de Hobbes a Locke. Rio de Janeiro: Paz e Terra, 1979. 
MARX, Karl. A questão judaica. São Paulo: Moraes, 1991. . Manuscritos económico-filosóficos (1848). Lisboa: Edições 70, 1993.

MÉSZÁROS, István. A crise estrutural do capital. São Paulo: Boitempo, 2009. (Col. Mundo do Trabalho.)

NETTO, José Paulo A construção do projeto ético-político do Serviço Social frente à crise contemporânea. In: Capacitação em Serviço Social e política social: Módulo 1 - Crise contemporânea, questão social e Serviço Social. Brasília: CFESS/Abepss/ Cead/UnB, 1999.

. Capitalismo e reificação. São Paulo: Livraria Editora Ciências Humanas, 1981. . Para a crítica da vida cotidiana. In: NETTO, José Paulo; FALCÃO, Maria do Carmo B. de Carvalho. Cotidiano: conhecimento e crítica. São Paulo: Cortez, 1987. ; BRAZ, Marcelo. Economia política: uma introdução crítica. São Paulo: Cortez, 2006. (Biblioteca Básica do Serviço Social.)

NISBET, Robert. O conservadorismo. Lisboa: Estampa, 1987.

OLIVEIRA, Francisco. O momento Lênin. Novos Estudos Cebrap, São Paulo, n. 75, jul. 2006.

ÓZ, Amóz. Contra o fanatismo. Lisboa: Asa Editores, 2007.

TRINDADE, José Damião de Lima. História social dos direitos humanos. São Paulo: Peirópolis, 2002.

PADILHA, Walquiria. Shopping center: a catedral das mercadorias. São Paulo: Boitempo, 2006.

WACQUANT, Loic. Punir os pobres: a nova gestão da miséria nos Estados Unidos. Rio de Janeiro: Revan, 2007. 